\title{
Cerebral aspergilloma in a child with autosomal recessive chronic granulomatous disease
}

\author{
A F Dean, I Janota, A Thrasher, I Robertson, G Mieli-Vergani
}

\begin{abstract}
A 2 year old girl presented with epilepsy 16 months after being diagnosed as having autosomal recessive chronic granulomatous disease. Computed tomography showed a cerebral mass which was surgically removed and proved histologically to be an aspergilloma. This case illustrates the application of molecular diagnostic techniques to the diagnosis of chronic granulomatous disease. The occurrence of, and unusual reaction to, cerebral aspergillus infection indicates the need to consider this possibility in the differential diagnosis of mass lesions in chronic granulomatous disease. Furthermore, it is clear that autosomal recessive chronic granulomatous disease cannot be considered to be a clinically mild form that is exempt from major neurological complications.

(Arch Dis Child 1993; 68: 412-414)
\end{abstract}

The chronic granulomatous diseases of childhood are a heterogeneous group of inherited disorders arising from a defect in the superoxide generating system of phagocytic cells, the NADPH oxidase. Five components of this system have now been identified and comprise two subunits of a membrane bound cytochrome (cytochrome $b$-245) and three cytosolic factors.' Defects in any of these components results in chronic granulomatous disease. Approximately two thirds of cases are due to defects in the cytochrome and are X linked, whereas one third are due to the absence of the 47 kilodalton cytosolic protein, $p 47$-phox, and have autosomal recessive inheritance. ' The clinical syndrome is characterised by extreme susceptibility to recurrent infection with certain micro-organisms. The tissues most often affected are the lymph nodes, skin, lungs, and liver; infection of the brain or its coverings is rare..$^{2-5}$

The case reported here is the first documented example of an intracranial aspergilloma in a child with chronic granulomatous disease.

Department of Medicine, University College

London

A Thrasher

Department of Neurosurgery, Maudsley Hospital, London

I Robertson

Department of Child Health, King's College Hospital, London G Mieli-Vergani

Correspondence to:

Dr A F Dean, Department of Neuropathology, Institute of Psychiatry, De Crespigny Park, Denmark Hill, London SE5 8AF.

Accepted 28 October 1992 group B streptococcus were isolated. Viral hepatitis, tuberculosis, leishmaniasis, and storage diseases were considered and excluded

\section{Case history}

A 2 year old black girl was admitted to hospital for the evaluation of epilepsy. She had been born in the UK of parents native to Zaire. The obstetric and neonatal history were normal and she was thriving when, at 8 months of age, hepatosplenomegaly and cervical lymphadenopathy was detected at a health check up. Venepuncture for blood tests caused an abscess to develop from which Staphylococcus aureus and a and an HIV antibody test (Bhering) was negative on three separate occasions. A diagnosis of chronic granulomatous disease was made.

The patient had four older siblings (two boys, two girls), all of whom were well. No other family history was available.

The patient did not report for follow up for the next year, but was then admitted to hospital after having two focal seizures within one month affecting the right side of her body. On examination she was afebrile and alert. There was decreased tone and brisk reflexes in the right arm and leg, with both plantar responses downgoing. There was an equivocal sensory loss in the right arm. Radiographic computed tomography examination showed a $3 \mathrm{~cm}$ lesion in the posterior frontal convexity of the left cerebral hemisphere that had homogeneously increased signal attenuation with respect to the brain, contained flecks of calcium, was surrounded by oedema, induced midline shift, and enhanced with contrast (fig 1). There were no contiguous air sinuses.

Five days after admission her right pupil began to react sluggishly to light and the right plantar response became upgoing. She was referred to neurosurgery and underwent a left frontoparietal craniotomy and excision of the mass.

At operation, there was a firm mass in the frontoparietal convexity. Near the midline on the top it had a site of dural attachment and peripherally a thin covering of brain; elsewhere, the mass could be dissected from the brain to leave a smooth surface. On incision some parts of the mass oozed caseous material. Almost all of the mass could be removed, leaving only a plaque of fibrous tissue attached to the dura and superior saggital sinus.

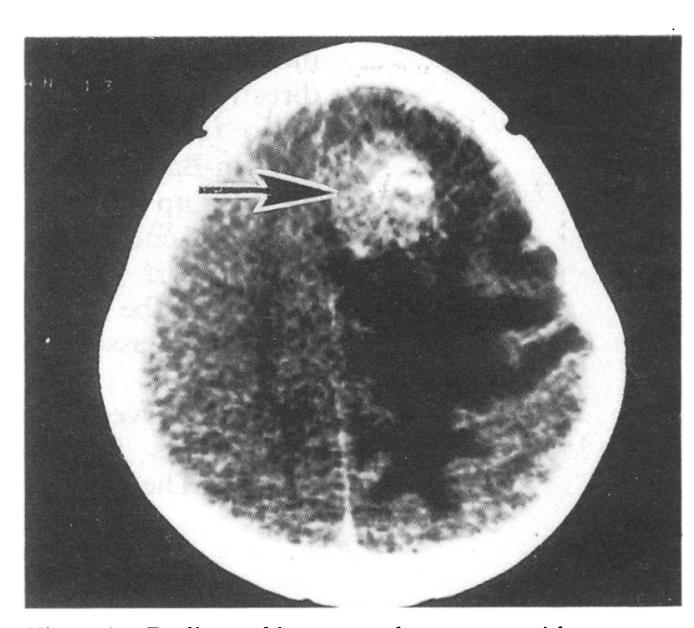

Figure 1 Radiographic computed tomogram without contrast of the cerebral mass (arrow). 
Figure 2 (A) Granuloma showing an epithelioid palisade around a core of polymorphs and amorphous debris (arrows) (haematoxylin and eosin stain $\times 80)$. $(B)$ Punctate basophilic bodies (arrow) within the cytoplasm of macrophages and epithelioid cells (haematoxylin and eosin stain $\times 320)$. $(C)$

Granuloma with a core of multinucleated giant cells (haematoxylin and eosin stain $\times 80$ ). (D) Hyphae within a granuloma core $($ Grocott stain $\times 320)$.
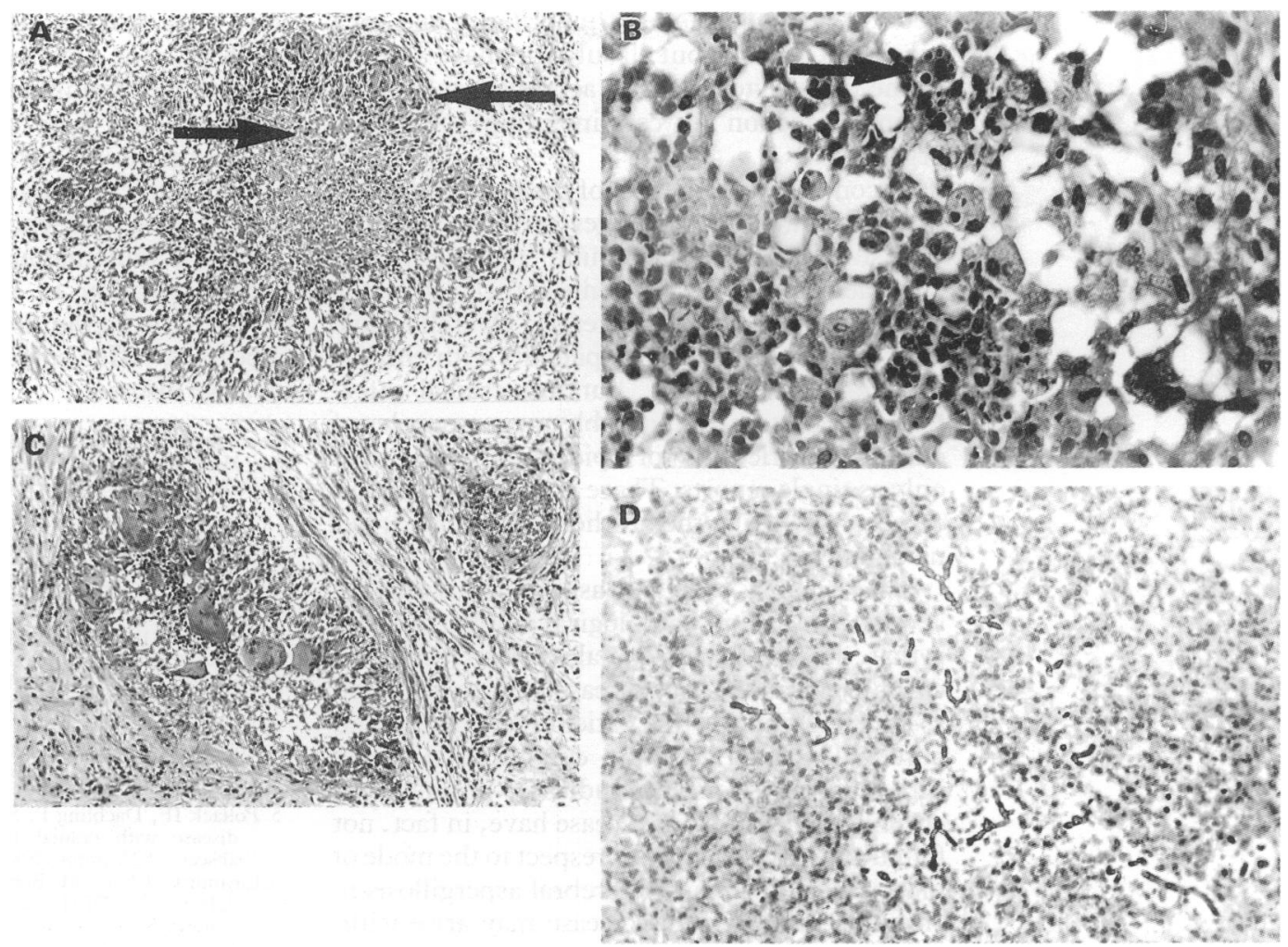

\section{Methods}

BIOCHEMICAL CHARACTERISATION

Neutrophils purified from peripheral blood were tested for the ability to produce superoxide using a NBT slide test and cytochrome $c$ reduction assay. Western blotting was carried out on postnuclear supernatants prepared from sonicated neurophils using polyclonal antisera against individual components of the NADPH oxidase. ${ }^{6}$

\section{HISTOPATHOLOGY}

Smears and a frozen section were prepared at the time of operation. Subsequent paraffin sections were stained with haematoxylin and eosin, ZiehlNielsen, Grocott, Giemsa, and for reticulin.

\section{BACTERIOLOGY}

Material obtained at operation was sent for culture of conventional bacteria, fungi, and acid fast bacilli.

\section{Pathology \\ BIOCHEMISTRY}

The diagnosis of autosomal recessive chronic granulomatous disease was made following a negative NBT slide test and absent superoxide production as measured by the reduction of cytochrome $c$. Western blotting showed the absence of the $p 47$-phox cytosolic protein, indicating a probable autosomal recessive form of the disease.

\section{HISTOPATHOLOGY}

Macroscopically, the material received was pale, firm, and gritty to cut. Microscopically, smears and the frozen section showed granulomata, giant cells, and necrosis, possibly due to tuberculosis. Subsequent paraffin sections showed numerous irregularly shaped granulomata fibrous tissue that was infiltrated with many plasma cells, some lymphocytes, and contained sparse small calcific concretions. In places the lesion was continuous with gliotic brain that was also stippled with calcium. Individual granulomata differed in appearance. Most consisted of a palisade of epithelioid histiocytes mingled with some macrophages and multinucleated giant cells, arranged around a core (fig 2A). Punctate, basophilic, Grocott negative material could often be seen in the macrophage element (fig 2B). The core usually consisted of polymorphs and macrophages in varying proportions and stages of disintegration. Rare cores consisted entirely of multinucleated giant cells (fig 2C). Acutely branching septate hyphae compatible with aspergillus species (fig 2D) were found in a few granulomata and in loose necrotic slough.

Other noteworthy features of the biopsy sample were the lack of vascular involvement by fungi and the absence of eosinophils.

\section{BACTERIOLOGY}

There was no significant growth of conventional bacteria nor fungi after three days in Sabouraud's medium. Culture for acid fast bacilli was negative at eight weeks.

\section{Discussion} cribed as a syndrome characterised by recurrent infections and granuloma formation primarily affecting the skin, lung, and reticuloendothelial system. ${ }^{*}$ The syndrome is now recognised to be ranging in size up to $0.3 \mathrm{~cm}$ lying within densely

Chronic granulomatous disease was first des- 
heterogeneous in mode of inheritance and on a biochemical basis, but all subtypes have a defect in the phagocyte oxidative activity that protects against infection by certain groups of microorganisms. ${ }^{9}$

In contrast with the rest of the body, infection of the brain and meninges is less common. Johnston and Newman found 'meningitis and septicaemia' in $17 \%$ of patients in their series, the agent invariably being bacterial. ${ }^{2}$ Overall fungal infection occurs in $20 \%$ of patients with chronic granulomatous disease, but intracranial infection appears to be remarkably rare; examples of chronic ventriculitis ${ }^{4}$ or epidural abscess ${ }^{5}$ exist only as single reports. There is one reference to a cerebral abscess in the brother of a proband, but no details are given. ${ }^{3}$

This report of an aspergilloma makes several clinical and pathological points. The first is that, despite the autosomal recessive variety of chronic granulomatous disease being considered as clinically mild, ${ }^{29}$ this patient had a major and potentially fatal infective complication at an early age. More recent studies of prognosis in chronic granulomatous disease have, in fact, not found any differences with respect to the mode of inheritance. ${ }^{10}$ Secondly, cerebral aspergillosis in chronic granulomatous disease may arise without there being an obvious primary focus of fungal disease. In this patient the chest radiograph was clear, there was no history of sinusitis or relation of the lesion to the sinuses, and the overlying bone was normal. Indeed, the child was remarkably well before presenting with epilepsy. In contrast, cerebral aspergillosis arising on a background of malignancy or immunosuppression is invariably associated with evidence of disseminated fungal disease. ${ }^{11}$ Thirdly, the pattern of reaction to aspergillus is noteworthy. When intracranial aspergillus infection occurs in the context of haematological malignancy or drug induced immunosuppression, the pathology usually includes vascular invasion with haemorrhagic infarction. In con- trast, the reaction in non-immunosuppressed subjects (for instance, related to chronic sinusitis) is granulomatous ${ }^{12}$; and that is the pattern found here and in a previous report of aspergillus epidural abscess ${ }^{5}$ occurring in a patient with chronic granulomatous disease. The overall $20 \%$ incidence of fungal infection in chronic granulomatous disease ${ }^{13}$ clearly indicates a predisposition to these organisms, but the proclivity to a granulomatous reaction ironically appears to offer some protection against more invasive disease.

We are grateful to Drs Cox and Dawson for radiological interpretation, Mr A Brady for his assistance with the illustrations and Mrs $M$ Chetty for the biochemical assays.

1 Segal AW. The electron transport chain of the microbicidal oxidase of phagocytic cells and its involvement in the molecular pathology of CGD. $\mathcal{F}$ Clin Invest 1989; 83: 1785 93.

Johnston RB, Newman SL. Chronic granulomatous disease Pediatr Clin North Am 1977; 24: 365-76.

3 Mills EL, Rholl KS, Quie PG. X-linked inheritance in female with chronic granulomatous disease. F Clin Invest 1980; 66 332-40.

4 Powers SK. Fenestration of intraventricular cysts using a flexible steerable endoscope and the argon laser. Neurosurgery 1986; 18: 637-41.

5 Pollack IF, Dachling P, Schuit KE. Chronic granulomatous disease with cranial fungal osteomyelitis and epidural abscess. F Neurosurg 1987; 67: 132-6.

6 Casimir C, Chetty M, Bohler M-C, et al. Identification of the defective NADPH-oxidase component of chronic granulomatous disease: a study of 57 European families. Eur 7 Clin matous disease: a study

7 Volpp BD, Nauseef WM, Clark RA. Two cytosolic neutrophil oxidase components absent in autosomal chronic granulooxidase components absent in autosomal

8 Berendes H, Bridges RA, Good RA. A fatal granulomatosis of childhood. The clinical study of a new syndrome. Minn Med 1957; 40: 309-12.

9 Tauber AI, Borregaard N, Simons E, Wright J. Chronic granulomatous disease: a syndrome of phagocyte oxidas deficiencies. Medicine (Baltimore) 1983; 62: 286-309.

10 Finn A, Hadzik N, Morgan G, Strobel S, Levinsky RJ Prognosis of chronic granulomatous disease. Arch Dis Child 1990; 65: 942-5.

11 Young RC, Bennett JE, Vogel CL, Carbone PP, DeVita PP. Aspergillosis. The spectrum of disease in 98 patients. Medicine (Baltimore) 1970; 49: 147-73.

12 Linares G, McGarry PA, Baker RD. Solid solitary aspergillotic granuloma of the brain: report of a case due to Aspergillus granuloma of the brain: report of a case due to Aspergillus
candidus and a review of the literature. Neurology 1971; 21 : candidus 177 .

13 Cohen MS, Isturiz RE, Malech HL, et al. Fungal infection in chronic granulomatous disease. The importance of the chronic granulomatous disease. The importance of the 66 . 